\title{
Las disputas del sindicalismo revolucionario por los gremios ferroviarios durante la primera posguerra
}

\author{
Cristian E. Aquino \\ UBA - CEHTI \\ ceaquino@gmail.com
}

La fragmentación del sindicalismo revolucionario en la primera posguerra obedeció a dos cuestiones fundamentales. Por un lado, como capítulo nacional de la recomposición de las izquierdas tras la Revolución Rusa y, por el otro, por razones locales relacionadas con los resultados de las prácticas estatales de arbitraje e incipiente intromisión en los asuntos internos de las estructuras gremiales por parte del radicalismo. En el contexto descripto, las distintas versiones del sindicalismo tuvieron en las querellas suscitadas entre 1920 y 1923 por la reorganización de los gremios ferroviarios, un terreno de batalla que exigió precisar sus concepciones en pugna. Por ello, interpretamos la creación de la Unión Ferroviaria (UF) como producto de las internas sindicalistas antes que producto de la influencia de La Fraternidad o del acercamiento al Partido Socialista y, por ende, a su competidora, la Federación Ferroviaria (FF), resultado de los esfuerzos organizativos del sector más radicalizado del sindicalismo junto a distintas variantes libertarias.

El principal punto de quiebre del sindicalismo lo encontramos en los cuestionamientos realizados por la Federación de Agrupaciones Sindicalistas Revolucionarias (FASR) a la estrategia de la central obrera de su corriente, la FORA IX, que aceptó y se benefició con sus vínculos con el radicalismo, y en los esfuerzos por incorporar a la doctrina sindicalista las novedades teórico-prácticas de la revolución de los soviets. A pesar de su relevancia, el primer antecedente historiográfico profesional lo encontramos en la obra de Bilsky (1984), quien describe a la FASR impulsando la reconfiguración de su corriente. Pittaluga (2016), sin dar cuenta de la anterior agrupación, precisa la especificidad de la crisis de esta corriente obrera. Doeswijk (2013) describe los contactos de los anarco-bolcheviques con el sindicalismo. Recientemente hemos reconstruido (Aquino, 2015) el itinerario e ideas de la FASR que reunía a los sindicalistas rojos. Por su parte, Ceruso (2015) reconoce que el 
acercamiento del sindicalismo con los "aliancistas" deriva del anarcobolchevismo para delimitar la estrategia "usista" y Koppmann (2017) considera el gremio de la madera dirigido por "rojos y autonomistas" eje de la USA.

Existen indicios para precisar la disputa sindicalista por los ferroviarios en la producción historiográfica de tres autores fundamentales. Hugo del Campo (2005) plantea que una vez constituida la UF se habría alejado a los ferroviarios de la USA por razones de tipo organizativo, vinculadas a la centralización antes que a cuestiones ideológicas. Ruth Thompson (1978) demuestra la permanencia de la influencia ácrata en las filas ferroviarias, considera a la UF la "lógica conclusión" del sindicalismo progresivamente reformista y legalista de la FORA IX y remarca la necesidad de no sobredimensionar los aspectos ideológicos. Hernán Camarero (2007), parcialmente de acuerdo con la tesis de Del Campo, plantea que la adscripción sindicalista de la UF, cuyas prácticas se irradiaron al resto de las organizaciones obreras, se correspondía con la neutralidad en la actividad gremial también promovida por los socialistas. Al cuadro general ofrecido por los autores citados consideramos imprescindible incorporar a la FASR, precisar el peso del PS en la formación de La Confraternidad Ferroviaria (LCF) y la UF y avanzar en las definiciones político-ideológicas de las luchas internas del sindicalismo que no pueden reducirse a mero oportunismo de astutos dirigentes ni a una mera práctica por la puja de poder dentro de las organizaciones.

Por último, nos proponemos demostrar que hacia 1922 el sindicalismo alojaba tres sectores con sus respectivas propuestas doctrinarias, prácticas organizativas y alianzas con otros segmentos del mundo gremial que disputaban la dirección de los ferroviarios, a los que proponemos denominar: sindicalismo rojo, sindicalismo forista y sindicalismo pragmático.

En el presente artículo exploramos, para los años 1920 a 1923, diversos órganos de prensa del sindicalismo como corriente: La Organización Obrera (LOO), La Batalla Sindicalista (LBS); del sector ferroviario: El Obrero Ferroviarios (EOF), La Confraternidad ( $L C)$, y de las centrales obreras: la Unión Sindical (US), Bandera Proletaria (BP), además del folleto ¿Qué es La Confraternidad?, escrito que se le encomendó a un periodista socialista pero avalado por los sindicalistas y los fraternales.

El trabajo se divide en cuatro secciones. La primera describe los avatares de los conflictos de los gremios ferroviarios liderados por los sindicalistas. En la siguiente analizamos la influencia del sindicalismo en el estatuto de La Confraternidad Ferroviaria. La tercera sección indaga los principales nudos del debate por la personería jurídica y las formas organizativas entre los sindicalistas. En el último apartado se precisan las prácticas gremiales de la UF y la FF. 


\section{Los sindicatos ferroviarios en disputa}

La principal organización gremial en la industria ferroviaria desde su fundación hasta la segunda década del siglo veinte fue La Fraternidad (LF). Fundada en 1887, reunía al selecto grupo de maquinistas, foguistas y limpia máquinas de las locomotoras. Estos oficios tenían la capacidad de paralizar el sistema ferroviario, reforzado por la estricta centralización y disciplina de sus afiliados. Persiguieron explícitamente fines corporativistas, legalistas y reformistas. Aunque sus dirigentes fueron afiliados o simpatizantes socialistas, nunca el gremio se definió como tal. Por lo expuesto, lograron constituir una temprana aristocracia obrera (Horowitz, 1984; Gordillo, 1988a). El resto de los oficios que requería la industria eran la contracara de los "fraternales".

Los operarios de los talleres (reparación y mantenimiento de los trenes), tráfico (guardias y empleados de estaciones) y Obras y Vias (mantenimiento) estaban prácticamente desorganizados, mal remunerados y bajo pésimas condiciones laborales. En el caso de los talleres diseminados por todo el territorio nacional, en algunos casos eran de gran tamaño y llegaron a concentrar miles de trabajadores. El segmento obrero que trabajaba en tráfico y obras estaban escasamente calificados, situación agravada por el trabajo de índole estacional para los segundos.

Los intentos por aglutinar a la totalidad de los ferroviarios no tuvieron éxito hasta 1912, tras la grave derrota de un conflicto sostenido por LF (Suriano, 1991; Gordillo, 1988a; Badaloni, 2005). Por lo cual comenzaron a respaldar los esfuerzos por erigir un gremio que aunara a las categorias obreras que no representaban. La Federación Obrera Ferroviaria (FOF), de observancia sindicalista, fue fundada el 5 de enero de 1912 pero recién se consolidó en 1915 gracias a la continua colaboración del gremio de los maquinistas que proveía lugares de reunión y facilitaba la circulación de sus organizadores. Intentaron implementar una federación sindical por rama de actividad, bajo la forma de federación, compuesta de seccionales de gran autonomía que a su vez se dividian según sus oficios, es decir, Tráfico por un lado y Talleres por otro (Godio, 1988). Francisco Rosanova, surgido del sector tráfico, fungió como secretario general desde los inicios de la FOF hasta su disolución en 1922.

La FOF contenía en sus filas diversas organizaciones político-sindicales en competencia exacerbada por la independencia de sus secciones, muchas de ellas incontrolables por su adscripción al anarquismo, otras que se declaraban autónomas y otras de los mismos sindicalistas revolucionarios, la mayoría de las veces más radicalizadas que sus direcciones. Por último, la heterogeneidad de sus bases dificultaba la unificación de sus reclamos. La dirección entrelazada de la FORA IX y la FOF intentó modificar esta situación impulsando algún grado de centralización, la 
unificación de los reclamos y el disciplinamiento interno, sin olvidar los intentos de acercamiento con los "fraternales" (Gordillo, 1988a y 1988b).

El resultado de las primeras elecciones bajo la Ley Sáenz Peña en 1916 llevó a la presidencia al radical H. Yrigoyen que introdujo la notable voluntad del gobierno por arbitrar a favor de ciertas fracciones del movimiento obrero. La novedad favoreció a los sindicalistas de la FORA IX, que habían demostrado prematuramente su disposición a la negociación y arbitraje estatal de los conflictos y, también, a aquellos gremios con particular capacidad de estrangular la economía agroexportadora como la FOF (para la experiencia de los gremios marítimos véase Caruso, 2016 y 2017). Ante esta situación, con la intención de fortalecer la capacidad negociadora de los ferroviarios en su conjunto, Francisco Rosanova impulsó con decisión los proyectos de unidad con LF.

En consecuencia, los ferroviarios protagonizaron en septiembre y octubre de 1917 y febrero de 1918 luchas masivas con altos niveles de violencia acompañadas de constantes fricciones internas. La FOF enfrentó a sus patronales, cuando pudo negoció con el Estado, pero su dirección sindicalista debió sumarse e intentar dirigir conflictos que prefirió evitar o alcanzar compromisos con rapidez. Sin embargo, gran número de estas luchas escaparon de su control fundamentalmente por la espontaneidad de los procesos de lucha recurrentemente orientados por grupos libertarios, el surgimiento de secciones que autodesignaban sus delegados para lanzarse a la huelga general y la reaparición de sindicalistas revolucionarios radicalizados y disconformes con la orientación de su corriente. Estos acontecimientos terminaron por agotar, atomizar y en los hechos destrozar a la FOF. Sobre esta experiencia que abarcaba los años 1917 y 1919 el personal dirigente sindicalista consideró llegado el momento de avanzar hacia reformas institucionales que garantizaran las decisiones de los cuerpos centrales mediante la reducción de la autonomía de las seccionales y el mayor control sobre sus bases e instituir lazos más fuertes con los "fraternales" (para la reconstrucción, características y resultados de los conflictos, véase Marotta, 1970; Thompson, 1978 y 1984; Rock, 1992; Falcón y Monserrat, 2000; Oliva y Menotti, 2015).

En mayo de 1920 la FOF reformó su estatuto para crear dos gremios de oficio articulados en el Sindicato de Tráfico y Talleres (STyT) con sus respectivos Comités Centrales (CC.CC.), verdadera apertura hacia la centralización y disciplina en sus filas. Pero el paso más elocuente para la reorganización se cumplió en el Primer Congreso Mixto en junio de 1920 que reunió a los distintos gremios de oficios de los ferroviarios. El 30 de junio quedó constituida LCF, que se propuso funcionar, hasta lograr la unidad, como coordinadora mediante una Junta Central (JC) de sus integrantes: LF y STyT. Esta decisión fue considerada el primer mo- 
vimiento de un proceso que desembocaría en la imposición de la unidad de los ferroviarios sobre las bases del modelo sindical corporativo de LF.

Mientras la organización entre los trabajadores del riel parecía confluir hacia su unificación, el sindicalismo revolucionario exponía sus diferencias internas. La ocasión para la confrontación se encontró durante el mes de marzo de 1922 en el V Congreso de Fusión. Los gremios de la FORA IX, sectores anarco-bolcheviques expulsados de la FORA V y autónomos crearon la Unión Sindical Argentina (USA). Si bien la nueva central fue considerada la continuación de la FORA sindicalista, encontramos que las rupturas no fueron menores. En primer lugar, agrupó a los sectores sindicalistas rojos y los llamados anarco-bolcheviques que, impactados por la Revolución Rusa, reformulaban a la luz de esta última sus pilares ideológicos e impulsaban el acercamiento de la central a la ISR. En segundo lugar, convencidos de la inmediatez de la revolución lanzaron la consigna de "todo el poder a los sindicatos", refrendado con el endurecimiento de la tradicional postura antipolitica dirigida a los referentes de los partidos socialista y comunista a los cuales objetaban su representatividad. En este punto debemos remarcar el alcance práctico del sindicalismo rojo. Por una parte, a pesar de la incorporación en el sindicalismo de nuevas reflexiones que revalorizaban la esfera política nunca abandonaron la centralidad de los gremios en su concepción del proceso revolucionario ni la desconfianza hacia los partidos obreros. Para esta corriente, la vanguardia no era sinónimo de partido leninista, por el contrario, podía adquirir otras formas como las Agrupaciones Sindicalistas que impulsaban localmente o la confederación gremial en sí misma (Aquino, 2015). Por otra parte, el objetivo de la conformación de una única gran organización obrera, de allí el nombre de la nueva central, permitía anteponer la unidad a la adscripción internacional si ello la ponía en peligro. Por último, en la nueva central obrera la dirigencia forista novenaria quedó desplazada, la Federación Obrera Marítima, organización insignia de la corriente, quedó debilitada, mientras el gremio de la madera adquiria una notable centralidad (Camarero y Ceruso, 2015; Koppmann, 2017) y los ferroviarios no se integraban a la central. La ausencia de los ferroviarios imponia a la USA el duro perjuicio de la pérdida de miles de potenciales afiliados, la imposibilidad de impulsar una gran federación del transporte y perdian el acceso a una organización de firme estructura nacional con capacidad para desorganizar el funcionamiento de la economía agroexportadora. Ahora bien, ¿el STyT fue expulsado o decidió no ingresar a la nueva central obrera? Aquí, sin arribar a una respuesta, queremos destacar dos cuestiones. Por un lado, los ferroviarios debatían el rol centralizador de los CC.CC. de Tráfico y Talleres ante numerosas seccionales que desconocian la validez de tal representación en nombre de la autonomía. Por otro lado, 
cuando esgrimían el respaldo de 15.000 obreros del riel despertaban fuertes sospechas de buscar controlar un congreso que repudiaba la orientación reformista de la FORA IX, que los principales dirigentes ferroviarios como Tramonti proponian consolidar y profundizar. Ahora bien, el Congreso rechazó la pretensión de los CC.CC. por 62 votos contra 42, ante lo cual sus delegados se retiraron mientras se los acusaba de indisciplina (Marotta, 1970: 59, 64-65 y 72). Dos meses después lo misma instancia superior del gremio desconoció la legitimidad de las decisiones resueltas en asambleas.

El segundo movimiento hacia la unificación (recordemos que el primero fue en 1920) fue la asamblea para reformar el estatuto de STyT de mayo de 1922, donde Antonio Tramonti planteó, tras previo acuerdo con LF, que la unidad definitiva se debía articular sobre la aceptación de la personería jurídica, la consolidación de mecanismos de mediación que en la práctica impedian la acción directa y una mayor centralización. El congreso rechazó tales propuestas con amplia mayoría de 63 votos contra 49 (datos en Marotta, 1960; Thompson, 1978; Gordillo, 1988b). La contra propuesta de estatuto se asentaba en el funcionamiento federativo de todas las actividades ferroviarias, el impulso a seccionales locales activas y democráticas y el repudio por principio de la personería jurídica. Propuestas que, en conjunto, amenazaban con la disolución del exclusivismo de LF, pero también contrariaba los intentos de disciplinamiento de la dirección sindicalista forista y, por ende, la FOF. Además, en un posterior Congreso Mixto se debatiria la adhesión a la recientemente creada USA.

La Junta Central de LCF, con el beneplácito de LF, desconoció las resoluciones de la asamblea impulsando en la Circular $\mathrm{N}^{\circ} 34$ un referéndum donde argumentaba que los delegados de la asamblea no expresaban el sentir de sus bases, cuestionando también la representatividad de algunas seccionales. ${ }^{1}$ Simultáneamente la USA, mediante la Circular $\mathrm{n}^{\circ} 4$, exigia mediante el pronunciamiento de las seccionales que se respeten las resoluciones de la asamblea. ${ }^{2}$ La respuesta del sector Tramonti y sus aliados fue inmediata, planteando la prioridad de la dirección de los gremios por encima de las instancias de democracia directa: "La USA por su intermedio, en la circular 4 sienta un precedente [...] funesto. [...] Se le niega derecho a la Junta Central para proponer a los afiliados un proyecto que a su juicio llena las necesidades bien sentidas del gremio, alegando que ese procedimiento significa alzarse contra resoluciones adoptadas en el congreso efectuado por Tráfico y

1. La Confraternidad, junio de 1922.

2. Unión Sindical, 3 de junio de 1922. 
Talleres" ${ }^{3}$ Más aún, reconoce que la mayoría habría votado en contra de su proyecto, pero "al votar la resolución aprobada de remitir a las secciones el proyecto de marras lo he hecho con toda conciencia porque sabía que no era ir en contra del Congreso de Tráfico y Talleres sino contra esa mayoria influenciada por un grupito de inmorales que negó derecho a los afiliados para dar su voto en una cuestión de la trascendencia de la que figuraba en el despacho de la minoría, por un grupito digo, en el cual han tomado parte activa elementos caracterizados de la USA". El grupo al que acusan de manipular la asamblea acaudillado por dirigentes de la USA rápidamente fue retratado como quienes se reunían "en la calle Rincón 369 local de la Agrupación Batalla Sindicalista". Indudablemente mencionaban de forma confusa a la conducción de la FASR, también conocida como Agrupación Sindicalista y su periódico La Batalla Sindicalista que además orientaban a la nueva central obrera. Poco tiempo después en el periódico de la USA el ferroviario José Morales se lamentaba de que "el congreso de TyT tuvo a último momento la debilidad de no nombrar un Comité Provisorio; y esa debilidad, sin duda alguna, resultará bastante cara al gremio puesto que toleran sobre sus espaldas las maniobras de los actuales dirigentes". ${ }^{4}$ Quizá para remediar el error táctico, este mismo dirigente desde la seccional Buenos Aires Oeste impulsó el reagrupamiento de los obreros del riel, para lo cual crearon el Comité de Relaciones que rápidamente fue reconocido por la USA como los "intérpretes de los ferroviarios". ${ }^{5}$ Finalmente la Junta Central, con el beneplácito de LF, convocaron en octubre de 1922 nuevamente a un congreso de LCF con delegados de Tráfico y Talleres y el primer Congreso Mixto. Allí sancionaron la adhesión a las resoluciones rechazadas en el congreso del mes de mayo con un reducido número de delegados, apenas 59 (casi todos de la provincia de Buenos Aires) cuyo voto favorable era conocido de antemano. Para alcanzar tal resultado unánime se utilizaron artilugios burocráticos como la exclusión de las seccionales que adeudaban sus aportes y la ausencia de delegados de los ferrocarriles como el Central Córdoba y Norte de simpatías con el sistema federativo. ${ }^{6}$

En respuesta, en enero de 1923 se fundó la Federación Ferroviaria (FF) que adhirió a la USA. Hacia julio de 1923 la UF logró la anhelada personería jurídica. De ahí en más hasta su ruptura en 1930 la CF, con los aportes de LF y la UF, se enfrentaba a una débil Federación

3. El Obrero Ferroviario, agosto de 1922.

4. Unión Sindical, 15 de julio de 1922.

5. Bandera Proletaria, 26 de septiembre de 1922.

6. La descripción pormenorizada de las manipulaciones para nombrar a los delegados al congreso en Gordillo (1988b). 
Ferroviaria que militaba en las filas de la USA reuniendo ácratas, comunistas y sindicalistas.

Como veremos, la división de concepciones gremiales estaba definida: por un lado, la entente de Tramonti y los fraternales con su propuesta centralista, legalista, estrechamente corporativa, frente a los sindicalistas rojos que exigian formas federalistas, antipolíticas, antiestatales y autónomas con el respaldo de la USA y los sindicalistas foristas desplazados de los lugares más relevantes de la nueva central obrera, aunque puntualmente algunos de sus dirigentes mantendrian su notoriedad y prestigio.

\section{La influencia sindicalista en el estatuto de La Confraternidad Ferroviaria}

En este apartado nos interesa analizar la configuración del sector sindicalista que hemos denominado forista novenaria a partir del folleto ¿Qué es La Confraternidad Ferroviaria?. ${ }^{7}$ Este breve texto de divulgación escrito en 1922 (recordemos que LCF se fundó a mediados de 1920) fue difundido y avalado por los gremios que la conformaban. La centralidad de este documento está dada, a nuestro entender, por manifestar, más allá de la estricta letra del articulado del estatuto fundante de LCF, algo más importante que es la interpretación oficial o impuesta como "lectura correcta" de los fundamentos, los medios y los fines de la nueva federación. También debemos remarcar que el texto fue escrito por el periodista socialista José Palmeiro que insiste en distintos pasajes sobre la influencia y coherencia del ideario de la sindicalista STyT. Además, este folleto fue difundido con grandes elogios por La Organización Obrera y El Obrero Ferroviario, representantes de la prensa sindicalista, con lo cual estaría expresando la orientación que el sector sindicalista forista intentaba imprimir a su STyT en el acercamiento con los fraternales, e identifica a sus opositores internos.

Primero, se alarma ante el riesgo que implica "el exagerado federalismo de que hacen gala en su organización [...] empuja [...] con demasiada frecuencia hacia conflictos inorgánicos, de los que salen cada vez más maltrechos", pero advierte que es inevitable "la disgregación [...] de los núcleos obreros que aún retienen bajo su égida los llamados "sindicatos autónomos" o "únicos" que están constituidos por ferrocarril en algunas empresas" (ídem: 17-18). También orienta sobre la adscripción a nivel internacional, que "podrá estar adherida a la entidad nacional de los trabajadores del país y que a su vez sea la rama de la

7. José Palmeiro, Qué es la Confraternidad Ferroviaria. Organización, objetivos, táctica, posición revolucionaria, Buenos Aires, 1922. 
Federación Internacional Sindical". Ambas propuestas eran rechazadas por la FASR, que en breve formarian la dirección de la USA para proponer el sostenimiento de las estructuras gremiales descentralizadas y la incorporación a la ISR. En tercer lugar, encontramos que el recién erigido STyT enunciaba como sus objetivos: “a) Defender y mejorar las condiciones económicas, morales, técnicas y sociales de los ferroviarios asociados; b) Preparar a éstos a asumir la gestión directa de la industria ferroviaria, de acuerdo con el principio de que los instrumentos del trabajo pertenecen al trabajador, c) Fomentar la solidaridad y la ayuda mutua entre los ferroviarios y los trabajadores en general" (ídem: 28). El folleto de Palmeiro también insiste en la capacitación técnica y en el conocimiento administrativo de la industria ferroviaria, citando para ello los acuerdos realizados entre los tres gremios de oficios: " $4^{\circ}$ ) capacitación técnica y general. $5^{\circ}$ ) asunción administrativa de la industria ferroviaria". Por último, hallamos la versión sindicalista revolucionaria de la historia sintetizada en el gradualismo y la capacitación técnica y moral de la clase obrera centrada exclusivamente en la esfera económica y en la producción para desmantelar el poder de la clase dominante: "Una revolución puramente política puede hacerse por medios exclusivamente coercitivos, catastróficos; mas no una revolución de consecuencias económico-sociales [...] la clase revolucionaria debe demostrar su superioridad técnico-económica sobre la clase dominante", como la misma burguesía en su época revolucionaria "fue realizando su emancipación a través de un largo periodo de tiempo preparatorio; acrecentando constantemente su poderío económico y socavando los cimientos de las instituciones políticas. Capacitándose, en suma" (ídem: 27; mi subrayado).

Nos parecen reveladoras las definiciones precisas que los sindicalistas foristas ofrecieron a los ferroviarios en una coyuntura en la cual las afirmaciones vertidas comenzaban a cuestionarse desde sectores como la FASR en vías de formación. Esta última, en medio del debate por la personería jurídica, no dudaba en recordar al grupo Tramonti la taxativa opinión vertida en el folleto que analizamos donde se afirmaba que solamente con su capacidad de presión o amenaza de acción directa le alcanzaba a LCF para obtener sus reclamos. ${ }^{8}$ La personería jurídica recibía el repudio de los sindicalistas rojos y foristas.

\section{Los grandes debates: personeria juridica y modelo de organización}

Las querellas de la corriente sindicalista en el gremio ferroviario fue-

8. Unión Sindical, septiembre de 1922. 
ron desarrolladas en relación a dos temas considerados estratégicos. El primer conflicto estaba vinculado al Estado: la aceptación o el rechazo de la personería jurídica cuestionaba explícitamente los métodos de lucha bajo la disyuntiva entre la ratificación de la acción directa o la aceptación abierta sin ambigüedades de la mediación o arbitraje estatal. El segundo tema de la querella estaba centrado en el modelo de organización: sindicatos industriales por empresa o la articulación de gremios por oficios, problemática a la cual se le agregaba el dilema entre las formas federalista o centralista. Detrás de cada uno de los temas mencionados previamente encontramos las exigencias de LF para avanzar hacia la unidad con las organizaciones ferroviarias sindicalistas.

La personería jurídica era la pieza fundamental e innegociable de los "fraternales", ya que sostenian que allanaba los acuerdos con la patronal predisponiendo favorablemente al Estado y certificando su vocación legalista y negociadora. También le adjudicaban haber facilitado la sanción de su primer convenio colectivo en 1920, que codificaba derechos y garantías, un escalafón, etc. El sector de Tramonti, con idéntico tenor, consideraba "indispensable la adopción para los $\mathrm{S}$ de TyT de un sistema de organización similar al de Tracción que explica las mejoras salariales, condiciones laborales, etc., superiores de los fraternales". ${ }^{9}$ La aceptación de LF como modelo a seguir implicaba que el sindicalismo aceptaba el terreno legal, aunque pretendía desmentir que tal giro conllevara la pérdida de su autonomía frente al Estado. Lo guiaban consideraciones de tipo práctico. Por un lado, "porque los ferroviarios estamos afectados a un servicio público, regido por leyes que debemos respetar, teniendo por diversas causas que recurrir ante el gobierno a reclamar su cumplimiento, por ser este el encargado de ejercer un control sobre los ferrocarriles, en razón precisamente de esas leyes". Por otro lado, "estando fuera de la ley nuestros reclamos debemos hacerlos en forma individual, porque nuestra organización al margen de la ley, las empresas no atienden a sus representantes, mientras que con personería jurídica podremos hacerlo colectivamente". ${ }^{10}$ Para sostener tal giro echaban en cara al gremio marítimo haber abandonado la confrontación directa con la patronal con el agravante de tener en su federación a secciones con personería jurídica: "La FOM tiene dos seccionales adheridas con personeria jurídica y que en todo momento se han portado tan revolucionariamente o tal vez más [...] ellas son: Centro de Maquinistas Navales y Capitanes de Cabotaje, Prácticos etc. [...] En lo que respecta de potencia a potencia es una mentira... Todos sabemos que el primer conflicto grande que sostuvo la FOM fue solu-

9. El Obrero Ferroviario, 1 de agosto de 1922.

10. El Obrero Ferroviario, 1 de agosto de 1922. 
cionado con la intervención del jefe de policía doctor Moreno, actual Ministro de guerra". ${ }^{11}$ Además atribuían cierta apatía de la mayoría de las bases ferroviarias a los sucesivos fracasos huelguísticos, a los que negaban toda inclinación combativa: "El gremio ferroviario necesita de la personería jurídica para ser atendido en sus reclamaciones y respetados los acuerdos que haga con las empresas y gobierno, por intermedio de sus representantes designados al efecto por la mayoria de los afiliados [...] esta misma mayoría no se encuentra dispuesta a tomar parte de ningún movimiento de fuerza [...] tiende día a día a hacerse más conservadora... desengañada por los últimos fracasos... están muy lejos de ser las vanguardias de los movimientos obreros". ${ }^{12}$

Los argumentos esgrimidos por el grupo Tramonti en clara alianza con LF y no poca presencia de la Comisión Socialista de Información Gremial (CSIG) parecerian desmentir su adscripción en la corriente sindicalista. Por el contrario, sostenemos que profundiza tendencias que emergian con contradicciones y mala consciencia en otros destacados dirigentes de su corriente. La aceptación más o menos abierta de la legalidad burguesa, o sea, la institucionalización de los gremios, pero evitando la injerencia total del Estado en sus filas, la permanente búsqueda de interlocutores en el Estado para presionar o equilibrar el poder patronal que implicaba la mediación recurriendo a actores gubernamentales, constituian rasgos sobresalientes de las prácticas no asumidas o revestidas de fraseología revolucionaria de la FORA IX. Francisco Rosanova, dirigente de lo más caracterizado de su tendencia y fundador de la FOF, afirmaba en 1920 como secretario general de LCF que "la Federación Ferroviaria declara que así como está dispuesto a combatir toda legislación restrictiva, aceptaría complacido una legislación que facilite el desarrollo de la organización sindical obrera, que legalice y extienda las conquistas alcanzadas por las mismas, y que por último ponga un límite al derecho ilimitado de explotación que hoy tiene el capitalismo". ${ }^{13}$ Un año después, el mismo dirigente, tras demostrar su desconfianza hacia las propuestas de legislación ferroviaria impulsada por el parlamento argentino, exigía que cualquier legislación se rigiera por la Convención de Washington fundadora de la OIT a la cual el gobierno habia suscripto (Caruso, 2014). Ahora bien, cuando la condición para aprobar la nueva legislación del trabajo ferroviario implicaba la imposición de la personería jurídica a La Confraternidad deja en claro que no la aceptarian. ${ }^{14}$ Agregamos que Rosanova fue un habitual co-

11. La Confraternidad, junio de 1922.

12. La Confraternidad, septiembre de 1922.

13. La Confraternidad, agosto de 1920.

14. El Obrero Ferroviario, 16 de mayo de 1921. 
lumnista de El Obrero Ferroviario, de los principales periódicos de su corriente y numen de la política de la FORA IX. El exhaustivo relevamiento de sus artículos en las prensas gremiales y sindicalistas no ha permitido hallar el menor atisbo de aceptación de la personería jurídica; cuando surge como problema inmediato no duda en repudiarlo. Nadie podría afirmar la influencia de agrupación extrasindical alguna sobre Rosanova. A lo cual agregamos que Tramonti tenía allanado el camino para su peculiar sindicalismo pragmático hecho de obras concretas pero indiferente a las contradicciones teóricas. Con sus propias palabras se definía a sí mismo: "Gano la partida precisamente callando la boca y dando a conocer las obras". ${ }^{15}$

En cambio, la aceptación de la legislación obrera desafiaba a los sindicalistas que bregaban desde la central gremial por recuperar el talante revolucionario de su corriente. Afirmaban que "las leyes sostienen el régimen actual y la acción obrera tiende a destruir y transformar ese régimen y finalmente, porque esas leyes restringen y obstruyen el libre desarrollo del movimiento obrero [...] toda forma de legalidad [...] es absolutamente incompatible con la organización obrera revolucionaria, porque esta está colocada al margen de la ley y por encima de la ley [...] al colocarse dentro de la ley anula su potencialidad combativa y es arrastrada a la colaboración con la burguesía". ${ }^{16}$ La negación de todo principio revolucionario contradecía la autonomía de un sindicato para culminar con la renuncia al mayor instrumento de la acción directa: "no es dueño de sí mismo, no puede accionar libremente contra la burguesía, no puede declarar una simple huelga [...] sin el visto bueno del procurador general de la nación; esto en los gremios anula toda aspiración revolucionaria, pierde su valor combativo como clase asalariada para convertirse en simple instrumento del estado". ${ }^{17}$

Los peligros de la personería jurídica se extendían hasta considerarla una trampa de la burguesía preocupada por no repetir el auge de la lucha de clases a la que se había enfrentado un par de años antes. Por ello denunciaban que "después de las grandes huelgas que se produjeron en el país, la burguesía reconoció la necesidad de dividir al proletariado e ideó varios métodos, siendo uno de ellos el seleccionar una pequeña cantidad de obreros a colocarla en situación más ventajosa de lo que goza la mayoria"; con salarios más elevados que la media "fácil es suponer que todo obrero que perciba ese sueldo no ha de tener mucha predisposición por la lucha y termine por alejarse de la organización y servir de puntal

15. El Obrero Ferroviario, agosto de 1922.

16. Unión Sindical, 17 de junio de 1922.

17. Unión Sindical, 10 de junio de 1922. 
a los capitalistas". ${ }^{18}$ Otro riesgo percibido fue: "La Personería Jurídica impone un carácter legislativo a la organización obrera y le impone cierto respeto a las leyes del estado y por tanto la imposibilidad para practicar la acción directa o cualquier forma de acción que no esté encuadrada dentro de la estructura de esa ley. La acción directa es el único medio de lucha que ha de conducirla a su finalidad, o sea la transformación social sobre bases más justas y más humanas". ${ }^{19}$

Los sectores que sustentaban a la FASR identificaron al grupo tramontista como el resultado de "El desgraciado contubernio de la antigua Federación Ferroviaria en una entidad política reformista" y una verdadera "camarilla autoritaria". ${ }^{20}$ Intentaron diferenciarse aclarando que trataban de inculpar al sindicalismo de corporativismo sin objetivo revolucionario. Este objetivo desconoce "la fundamental diferencia que media entre sindicalismo revolucionario que anhela la transformación económica y política de la sociedad presente y el otro sindicalismo mejorista, único y exclusivamente". Por un lado el sindicalismo revolucionario y por otro en oposición sindicalismo reformista. En esa confrontación el sindicalismo rojo encontraba aliados para divulgar su peculiar sindicalismo bolchevizado e impedir que los elementos reformistas y políticos se apoderara de las organizaciones obreras: "Nos valeremos de las fracciones anarquista unionistas y sindicalista revolucionaria. [...] En la discusión y aprobación de la carta orgánica de la USA las dos fracciones han estado de acuerdo en todo hasta en la finalidad". ${ }^{21} \mathrm{El}$ acercamiento entre ambas corrientes encontraba su unidad en "la concepción igual en la lucha de clases [...] la orientación revolucionaria antiestatal y antipoliticas de nuestro movimiento obrero". ${ }^{22}$

El otro gran tema de la disputa sindicalista tenía como eje la reestructuración de las organizaciones ferroviarias constituidas por oficio en gremios por industria bajo el principio centralista o federalista. Imponer uno u otro modelo definía cuán democrática y autónoma serían las seccionales y las bases obreras, problemática que se entrelazaba con la percepción del avance de procesos de burocratización de los organismos de clase. El rígido centralismo que auspiciaban desde LCF y la señera LF secundada por el gremio de los Talleres se contraponía al sistema federalista que impulsaban desde la FASR apoyada por la USA. Esta última pretendía organizar secciones que gozaran de gran autonomía

18. Bandera Proletaria, septiembre de 1922.

19. Unión Sindical, junio de 1922.

20. La Batalla Sindicalista, 6 de marzo de 1922.

21. Unión Sindical, 10 de abril de 1922.

22. Unión Sindical, 10 de abril de 1922. 
creadas a partir de cada una de las empresas de ferrocarriles, donde la diferenciación entre tracción, talleres y tráfico se disolvía.

La USA, a pesar de su insistencia en el sistema federalista para los sindicatos de industria, negaba la vinculación directa entre sindicato por rama con el centralismo y los gremios por oficio con el federalismo. Para el caso ferroviario afirmaban: "los sindicatos de rama o industria, pueden y deben constituirse sobre el federalismo más amplio". ${ }^{23}$ Insistían en que las direcciones imprimian a las organizaciones su espiritu más o menos revolucionario, es decir, el carácter federalista o centralista no derivaba del orden industrial ni le era consustancial. En este punto de la exposición es necesario plantear que el énfasis en recomendar el federalismo para las filas de los ferroviarios respondería a su utilización circunstancial para debilitar a La Confraternidad Ferroviaria diluyendo el poder del sector tracción eje de LF. Los sindicalistas tempranamente habian llamado a la centralización en sus principales organizaciones para lograr la mayor cohesión organizativa factible.

El sector de Tramonti que impulsaba la estricta centralización identificaba al federalismo con la dispersión organizativa, el responsable de derrotas y la falta de unidad tanto por motivos ideológicos como por personalismos: "Con el centralismo y personería jurídica conseguirá la verdadera organización ferroviaria con cuerpos centrales dotados de mayor austeridad y confianza de parte de los asociados, a quienes estos podrán responsabilizar de sus actos, evitándose el espectáculo vergonzoso de que haya, como en la actualidad, tantos directores e intérpretes de las necesidades del gremio como caudillejos sienten sus reales en las secciones". ${ }^{24}$

Para Tramonti y su grupo la UF debía impulsar la consolidación del estrato dirigente junto a la disciplina de las bases. Ambas medidas eran consustanciales con el proyecto de reorganización gremial estrictamente centralista y la utilización de formas de lucha que pretendían evadir el conflicto abierto con el fin de no poner en riesgo la estructura gremial. Esta metodología instaba por presionar mediante medidas como el trabajo a reglamento evitando las huelgas y la demostración de cohesión de grandes masas de afiliados antes que confrontar abiertamente con las patronales y el Estado.

\section{La unión y la federación: mecanismos de burocratización en las organizaciones ferroviarias}

Apenas fundada la UF se impulsaron nuevas prácticas administrati-

23. Unión Sindical, 1 de mayo de 1922.

24. El Obrero Ferroviario, marzo de 1922. 
vas coherentes con la centralización organizativa, y a la vez se remarcaba la distancia jerárquica entre dirigentes y dirigidos. La administración eficiente exigió la contratación de un contador, es decir un profesional, donde previamente un militante cumplía la función de tesorero. E1 mecanismo de cobranzas de la cuota sindical fue centralizado. Para la oficina administrativa compraron nuevo mobiliario, toda clase de elementos de oficina entre los cuales se destacaban los ficheros que albergaban los datos de la matriculación de todos los afiliados. Además registraron las firmas para garantizar su autenticidad en vistas a futuras votaciones generales. ${ }^{25}$ Los lazos entre los dirigentes y los delegados de base y la generalidad de los afiliados fueron explícitamente jerarquizados, acentuando su distancia. Esta encuentra su modelo en la siguiente anécdota, ocurrida durante el primer Congreso Mixto, con inocultable fin ejemplificador: "Cuando la Junta Central por intermedio de su delegación interrumpió, por decirlo así, la marcha normal de las deliberaciones del congreso a que nos referimos, fue escuchada con total atención y deferencia, porque esos delegados sabían que tenían el deber de escuchar la palabra del cuerpo superior de la organización, porque su propia condición de tal... no cabía otra cosa". ${ }^{26}$ Del mismo tenor, pero en relación al surgimiento de la figura de Tramonti como caudillo inapelable, casi indiscutible, condujo a la afirmación exasperada de un ferroviario opositor: "A Tramonti todos le dicen que sî". ${ }^{27}$ Además los opositores eran hostilizados o expulsados y llegado el caso las seccionales díscolas desarticuladas. ${ }^{28}$ Por último, los vínculos de la nueva organización ferroviaria con el Estado concretada con la obtención de la personería jurídica tuvo el llamativo correlato de la inédita denuncia penal impulsada por Antonio Negri contra el periódico comunista La Internacional al cual acusó de difamación. ${ }^{29}$ Todo indicaba que los capitostes ferroviarios de los talleres con sus pretensiones de disciplina, jerarquía y centralización llegaban para quedarse.

La contracara de la incipiente burocratización descripta para la UF fue, al menos para el período que estamos analizando, la creación de la Federación Ferroviaria. La ruptura comenzaba en la seccional Buenos Aires Oeste, cuya Comisión Directiva publicó las resoluciones de su Asamblea del 19 de septiembre: “1) Separarse de la Confraternidad si el congreso mixto aprueba la personería jurídica 2) Adhesión al Comité de Relaciones de la Federación Ferroviaria. 3) Ponerse de acuerdo con las

25. El Obrero Ferroviario, noviembre de 1922.

26. La Confraternidad, junio de 1922.

27. El Obrero Ferroviario, noviembre de 1922.

28. El Obrero Ferroviario, noviembre de 1922.

29. El Obrero Ferroviario, noviembre de 1922. 
secciones Liniers y Tablada para constituir el Sindicato de F.C. Oeste". ${ }^{30}$ El siguiente paso consistió en la concreción del Comité de Relaciones que fue decidida por el trato dado a la seccional Rosario del FCCA, donde, tras rechazar masivamente la personería jurídica, surgió una seccional paralela favorable a la UF. La segunda circular del Comité se pronunció por "sostener los acuerdos del primer congreso de Tráfico y Talleres... desconocidos por los amorales dirigente de la Confraternidad" ${ }^{31} \mathrm{El}$ objetivo era la "unidad de todos los ferroviarios en una sola organización [...] que desaparezcan los Sindicatos de Tráfico, Talleres y Tracción para constituir una sola organización ferroviaria [...] un solo sindicato de la industria ferroviaria", es decir la federación de los sindicatos por empresa. Al Comité de Relaciones lo conformaron en sus inicios las "secciones de la Capital y circunvecinas contrarias a la personería jurídica: Buenos Aires, Liniers y Tablada del F.C. Oeste, Buenos Aires, San Martín y Victoria del FCCA (autónoma), Talleres Sud (autónoma), etc.". Las seccionales autónomas revelan la presencia de la tradición libertaria de claro perfil anarcosindicalista entre los obreros del riel, que serán agrupadas en las Secciones Autónomas Unidas. El tercer sector que confluye en la formación de la FF son desprendimientos del STyT.

El primer sindicato de industria por empresa surgió en el FCCA Rosario tras su congreso fundador de fines de noviembre de 1922, donde los anarcosindicalistas confluyeron con el sindicalismo rojo. Las sesiones del congreso con la presencia de las barras, la discusión colectiva de cada artículo del estatuto en gestión, la celosa afirmación de la autonomía de las secciones, la insistencia en el método asambleario, los recaudos de rotación de los representantes, la sugerencia de impulsar escuelas racionalistas y el minucioso debate sobre la finalidad del nuevo sindicato industrial contrastaban con la orientación de la UF a la vez que imprimía matices libertarios a los esfuerzos organizativos del Comité.

La adscripción al Comité no fue sancionada de forma inmediata, más bien pareció la única posibilidad ya que era "el único organismo que existe para la coordinación de los esfuerzos que se realizan para reorganizar la Federación Ferroviaria". La postura definitiva no implicaba su incorporación sino su articulación con una instancia organizativa. "De acuerdo con la finalidad que persigue el Comité [...] es la constitución de Sindicatos por ferrocarril, el congreso aprueba prestarle todo el apoyo moral y material que esté a nuestro alcance". ${ }^{32}$ A pesar de las reticencias hacia el Comité, la adhesión a la USA no fue cuestionada.

La confluencia inicial del mencionado Comité, brazo ferroviario de

30. Bandera Proletaria, 1 de noviembre de 1922.

31. Bandera Proletaria, 22 de septiembre de 1922.

32. Bandera Proletaria, diciembre de 1922 
la USA, algunas secciones rebeldes de la STyT y el gremio industrial de la FCCA crearon en enero de 1923 la Federación Ferroviaria. El desempeño de la nueva federación alcanzó cierta expansión en los años siguientes, pero apenas pudo competir con la avasalladora UF para disolverse en 1927.

\section{Conclusiones}

El recorrido realizado por las querellas en el interior del sindicalismo revolucionario nos permite trazar las principales características de sus tendencias en competencia.

El primer grupo al que denominamos sindicalismo rojo surgió como amalgama de las afinidades entre sindicalistas y bolcheviques. Crearon la FASR desde la cual impulsaron la formación de la USA y la FF en colaboración con anarco-bolcheviques y anarcosindicalistas. Infructuosamente intentaron acercar la novel central obrera a la ISR. En relación a la reorganización de los ferroviarios propusieron gremios por empresa vinculados en una vasta federación cuyas seccionales gozaran de autonomía, reafirmaron la lucha de clases como único método de acción e impulsaron su incorporación a la USA. A pesar de la vasta reflexión para incorporar las novedades de la revolución rusa, sus más estacados dirigentes Pellegrini y Lotito jamás ofrecieron una teorización que desalojara al sindicato en su condición de institución base del socialismo.

El segundo grupo, al cual denominamos sindicalismo pragmático, tuvo su principal exponente en Antonio Tramonti que desarrolló su actividad gremial exclusivamente entre los trabajadores del riel. Su inclusión en esta corriente podemos caracterizarla a partir de la prescindencia política entendida como autonomía de los partidos políticos, el gremio como única legítima institución obrera en clave cerradamente corporativista y el reformismo sin eufemismos. Impusieron a los ferroviarios un modelo gremial afin a LF, es decir, fuertemente centralizado con personeria jurídica que evitara la acción directa y la autonomía ante la USA.

El último sector al que llamamos sindicalismo forista en clara alusión a la FORA IX contaba entre sus filas a fundadores de la misma corriente y la FOF. Para nuestra investigación el caso paradigmático fue Francisco Rosanova, conspicuo dirigente ferroviario. En los principales órganos de propaganda del sindicalismo sustentó la estrategia hacia el radicalismo, criticó la revolución de los soviets, defendió la adhesión de la central obrera a la Federación Sindical Internacional (FSI) y a la Organización Internacional del Trabajo (OIT). Profesaba cierta visión reformista que ocultaba en una hueca fraseología revolucionaria. Sin embargo, periódicamente revivía posturas principistas, quizás lejanos ecos de un pasado antisistémico. Entre los ferroviarios propusieron des- 
de el principio del debate el rechazo principista a la personería jurídica que circunstancialmente los aproximó a la USA. Lo mismo sucedió ante los ataques de la CSIG y el PS a la trayectoria de la FORA IX y la USA al punto que Marotta escribió en Bandera Proletaria para defender el buen nombre y honor del sindicalismo revolucionario. ${ }^{33}$

Hemos dicho anteriormente que la organización que impusiera su control a los ferroviarios tenía la posibilidad de dirigir al movimiento obrero en general y posicionarse en un punto de gran fragilidad del capitalismo argentino. La corriente "tramontista", de escuálida formación teórica, con lazos utilitarios con LF y el PS, podemos caracterizarla como el principal obstáculo para que la USA y la FASR lograran dirigir al conjunto del movimiento obrero. Así, definió el pobre desempeño posterior de la USA que fracasó en su intento por sumar a sus filas a los ferroviarios. Otra consecuencia fue la profundización de los desacuerdos entre las fracciones del sindicalismo en competencia, que pretendian imponer recorridos alternativos al movimiento obrero en su conjunto. Los dirigentes "foristas" perdieron toda influencia decisiva en la novel central obrera. Entre sus cuadros más destacados, pero menos perjudicados por la debacle, como el ferroviario F. Rosanova o Fortunato Marinelli de la prestigiosa FOM, mantuvieron una llamativa cautela.

Por último, las prácticas que hicieron posible la creación de la UF denotan un proceso de burocratización: desconocieron asambleas, proponían en los estatutos cláusulas que terminaba con la autonomía de las seccionales, con la personería jurídica convalidaron la injerencia estatal en los gremios, su horizonte político se reducía a la firma de convenios colectivos de trabajo y proponían tribunales laborales para evitar la acción directa. Con no pocas razones Antonio Tramonti fue convertido por sus oponentes en el exponente de burócrata de una organización estrechamente corporativa, legalista y negociadora. Una vez creada la UF tempranamente alcanzó el reconocimiento estatal mediante la sanción de la personería jurídica, la aprobación de su convenio colectivo y la institucionalización de la mediación gubernamental. Con el tiempo se erigió como el gremio más poderoso de Argentina gracias a su cantidad de afiliados y sólidas finanzas que permitian ofrecer servicios de salud, centros recreativos, caja de jubilación entre otros servicios, el acceso al consumo, etc. En conjunto alcanzaban la respetabilidad admirada de los fraternales.

\section{Bibliografia}

Aquino, Cristian E. (2015), "Bajo la influencia de la Revolución Rusa. La 
Federación de Agrupaciones Sindicalistas Revolucionarias a través de La Batalla Sindicalista 1920-1923", Archivos, año III, nº 7, pp. 123-142. Badaloni, Laura (2005), "El saber como forma de resistencia y conformación de una identidad. La fundación de la Escuela de Foguistas, Maquinistas y Personal de Locomotoras de la sección Rosario del FCCA", X Jornadas Interescuelas, Rosario.

Bertolo, Maricel (1993), "El sindicalismo revolucionario y el Estado (19041922)", en Cuaderno del CIESAL, Rosario, año $1, \mathrm{n}^{\circ} 1,2^{\circ}$ semestre de 1993, pp. 49-62.

Bilski, Edgardo (1984), La Semana Trágica, Buenos Aires: CEAL.

Camarero, Hernán (2007), "Socialismo y movimiento sindical: una articulación débil. La COA y sus relaciones con el PS durante la década de 1920", en Hernàn Camarero y Carlos M. Herrera (eds.), El Partido Socialista en Argentina. Sociedad, politica e ideas a través de un siglo, Buenos Aires: Prometeo.

Camarero, Hernán y Diego Ceruso (2015), "Una historia del sindicato de la madera: organización gremial e influencia de la izquierda en las luchas obreras, Buenos Aires, 1917-1943", en e-latina. Revista electrónica de estudios latinoamericanos, vol. 13, $\mathrm{n}^{\circ} 50$.

Caruso, Laura (2017), "La Unión del Marino: la prensa gremial marítima, una lectura obrera sobre la cuestión social, la ley y los derechos (19111928)", en Ricardo González Leandri y Juan Suriano (eds.), La cuestión social y sus itinerarios de difusión a través de las publicaciones periódicas argentinas, 1870-1930, Rockville: Global South Press.

- (2016), Embarcados. Los trabajadores maritimos y la vida a bordo: sindicato, empresas y Estado en el puerto de Buenos Aires (1889-1921), Buenos Aires: Colección Archivos, Imago Mundi.

- (2014), "La politica laboral argentina en la inmediata posguerra: una perspectiva internacional, 1907-1925”, Relaciones, Zamora, n ${ }^{\circ}$ 138, pp. 11-43.

Ceruso, Diego (2015), La izquierda en la fábrica. La militancia obrera industrial en el lugar de trabajo, 1916-1943, Buenos Aires: Colección Archivos, Imago Mundi.

Del Campo, Hugo (2005), Sindicalismo y peronismo. Los comienzos de un vínculo perdurable, Bueno Aires: Siglo XXI.

Doeswijk, Andreas L. (2013), Los anarco-bolcheviques rioplatenses, Buenos Aires: CeDinCi.

Godio, Julio (1988), El movimiento obrero argentino (1910-1930). Socialismo, sindicalismo y comunismo, Buenos Aires: Legasa.

Gordillo, Mónica (1988a), La Fraternidad en el movimiento obrero: un modelo especial de relación (1916-1922), Buenos Aires: CEAL.

- (1988b), El movimiento obrero ferroviario desde el interior del pais, 1916 1922, Buenos Aires: CEAL.

Horowitz, Joel (2015), El radicalismo y el movimiento popular, 1916-1930, Buenos Aires: Edhasa. 
- (1984), "Los trabajadores ferroviarios en la Argentina (1920-1943). La formación de una elite obrera”, en Desarrollo Económico, vol. 24, n 94, 1984.

Koppmann, Walter (2017), "Experiencia de lucha y formas de estructuración gremial de los trabajadores de la madera y el mueble de la ciudad de Buenos Aires, 1915-1930", Izquierdas, $\mathrm{n}^{\circ} 33$, abril-mayo.

Marotta, Sebastián (1970), El movimiento sindical argentino, su génesis y desarrollo. Buenos Aires: Calomino.

Oliva, Antonio y Paulo Menotti (2015), “El poder de la turba'. La lucha de los trabajadores ferroviarios del Central Argentino. La FOF, La Fraternidad y las contiendas del poder gremial en el seno del movimiento obrero (1917-1918)", Archivos, Buenos Aires, año III, n 6, pp. 117-137.

Pittaluga, Roberto (2016), Soviets en Buenos Aires. La izquierda de la Argentina ante la revolución en Rusia, Buenos Aires: Prometeo.

Rock, David (1992), El radicalismo argentino, Buenos Aires: Amorrortu.

Suriano, Juan (1991), "Estado y conflicto social. El caso de la huelga de maquinistas ferroviarios de 1912", en Boletín del Instituto de Historia Argentina y americana Dr. Emilio Ravignni, Buenos Aires, ${ }^{\circ} 4$.

Thompson, Ruth (1978), Organized Labour in Argentina. The Railways union to 1922, tesis doctoral, St. Antony's College, Oxford.

$* * *$

Titulo: The disputes of revolutionary syndicalism for the railway unions during the first postwar period

Resumen: El presente artículo explora las disputas del sindicalismo revolucionario en torno a la organización de los gremios ferroviarios durante los primeros años de la década de 1920. Nos centramos en los debates sobre la personería jurídica y el modelo de sindicato industrial centralizado o federativo. Sostenemos que estas disyuntivas derivaron en la fragmentación de la corriente en tres sectores a los cuales proponemos denominar sindicalismo rojo, sindicalismo forista y sindicalismo pragmático.

Palabras clave: Sindicalismo revolucionario - ferroviarios - modelos sindicales

Abstract: This article explores the disputes of revolutionary syndicalism around the organization of railroad unions during the first years of the 1920s. We focus on the debates about legal status and the model of centralized or federative industrial union. We argue that these disjunctives led to the fragmentation of the current in three sectors to which we propose to denominate red syndicalism, forist syndicalism and pragmatic syndicalism.

Keywords: Revolutionary syndicalism - railway unions - union models

Recepción: 13 de febrero de 2017. Aprobación: 15 de marzo de 2017. 